Vol No: 4, Issue: 1

Received Date: Jun 2, 2019

Published Date: Jun 28, 2019

\section{Cristina García-Muro}

\section{Eduardo Esteban-Zubero²}

Cristina Toledo-Gotor ${ }^{1}$

Diego Viguera-Elías ${ }^{1}$

Aranzazu Olloqui-Escalona ${ }^{1}$

\section{Verónica Jiménez-Escobar ${ }^{1}$}

'Department of Pediatrics, Hospital San Pedro, Spain.

2Emergency Department, Hospital San Pedro, Spain.

\section{Corresponding Authors:}

\section{García-Muro C*}

\section{Esteban-Zubero $E^{*}$}

Hospital San Pedro, Logroño, Spain

\section{Acute Hemorrhagic Edema of Infant: A Case Report}

\section{ABSTRACT}

Acute hemorrhagic edema of infant is an infrequent leukocytoclastic vasculitis clinically characterized by macules, papules or urticarial lesions which progress to purpuric plaques. It is a vasculitis of small vessels mediated by immunocomplexes, and usually associated with bacterial or viral infections. The diagnosis of this entity is essentially clinical, and it is important to take it into account to avoid the systematic use of complementary tests. Its course is usually self-limiting and benign, without requiring specific treatment.

We present the case of a 2-month-old infant with this condition associated to upper respiratory infection. The infant presented favorable evolution with resolution of the cutaneous symptomatology in a few days without specific treatment.

Keywords: Acute Hemorrhagic Edema; Leukocytoclastic Vasculitis; Immunocomplexes.

\section{INTRODUCTION}

Acute hemorrhagic edema of the infant (AHEI) is an infrequent leukocytoclastic vasculitis. It is characterized by the presence of erythematous or purpuric skin lesions, predominantly in face and extremities [1]. It presents a benign course and disappears spontaneously in a few days or weeks [2]. We report a case from which we will made a brief review of this pathology.

\section{CASE REPORT}

A 2-month-old male infant with a previous 4-day history of upper respiratory infection consulted because of a sudden onset of generalized purpuric maculopapular lesions, predominantly in the facial region and acral areas, with skin involvement of palms and plants (Figure 1).

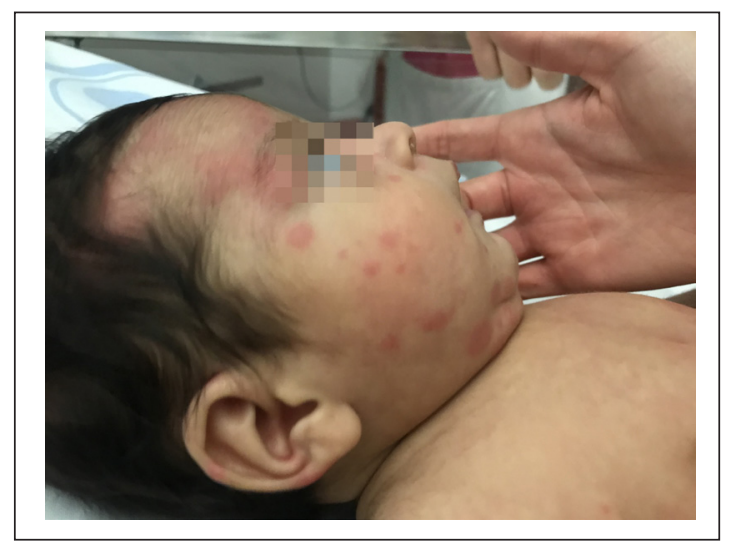


He also associated facial edema that included both auricular pavilions. He presented very good general condition, just referred a single febrile peak of $38.5^{\circ} \mathrm{C}$ before the appearance of the rash, remaining afebrile afterwards. Cutaneous lesions evolve to coalescent plaques and some acquire annular morphology. There was no digestive symptomatology. He was breastfeed from birth (Figure 2). A basic blood test was performed, showing mild leukocytosis with lymphocytosis and moderate thrombocytosis, with normal renal and hepatic function. Cultures of nasopharyngeal aspirate were extracted being negative, whereas the virology studies were positive to Rhinovirus. Cow's milk proteins Allergy was ruled out.

The symptomatology was disappearing progressively in 6 days with symptomatic treatment, without residual skin lesions.

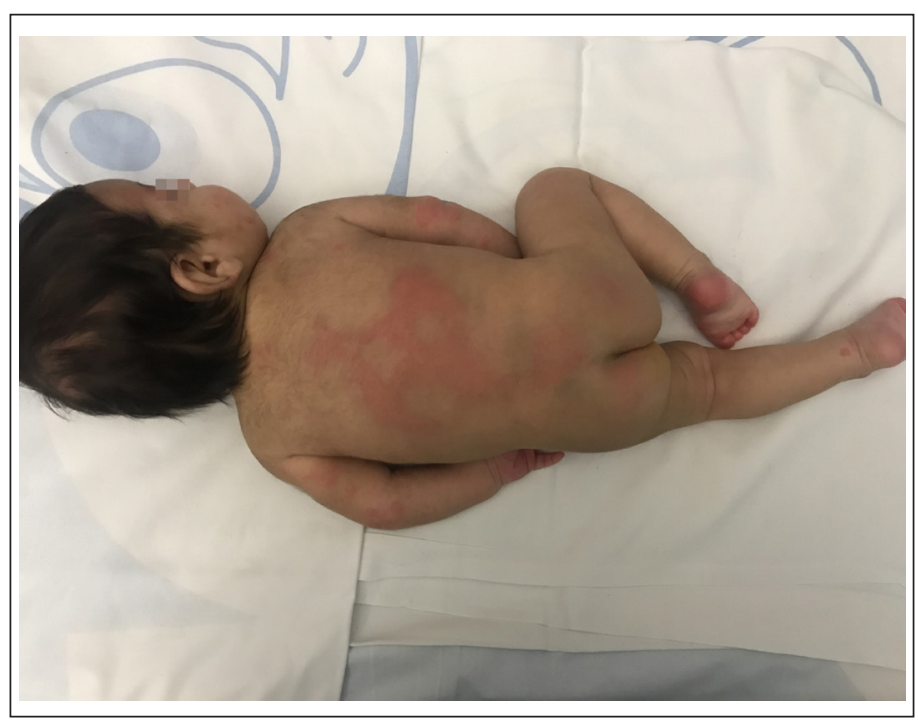

\section{DISCUSSION}

AHEI is a leukocytoclastic vasculitis. It was described for the first time in 1913 [1]. It is an infrequent disease whose actual incidence is unknown. It generally affects males between 4 months and 2 years [2], being exceptional its appearance below this age, like in the case reported. Its highest incidence occurs during the winter months due to the higher incidence of respiratory infections during this time of year [3].

It is a small vessel vasculitis mediated by immunocomplexes, usually triggered by a bacterial or viral infection [3], although it has also been described associated with different medications such as antibiotics or vaccine administration $[4,5]$. In our patient, we can establish a temporal association between upper respiratory tract infection and the cutaneous symptomatology. We assume a viral etiology due to the virology test performed on the nasopharyngeal aspirate was positive to Rhinovirus.

Most common clinical manifestation of AHEI is the sudden onset of skin lesions. Clinical manifestations initially consist of small macules, papules or urticarial lesions, which quickly evolve to large palpable purpuric plaques or target lesions. These may acquire a large skin extension [6]. They usually show a symmetrical distribution and generally affect lower limbs and facial area, with subsequent extension to the rest of the body. Sometimes it may associate edema in auricular pavilions, face or extremities (most frequently back of hands and feet) [7], being these signs, when they appear, highly suggestive of this entity. Fever, which is usually low grade, may be present in up to $50 \%$ of cases. Other less common symptoms are pruritus, irritability, abdominal pain, vomiting, arthralgias or scrotal edema [8]. Renal involvement is infrequent, although cases with isolated and transient hematuria or proteinuria have been described [9].

Laboratory results are not specific. Leukocytosis with neutrophilia or lymphocytosis can be found, as the case reported, in addition to elevated C-reactive protein and erythrocyte sedimentation rate [10]. The elevation in the number of platelets, as in our case presented, and peripheral eosinophilia, are also described in patients with acute hemorrhagic edema [11].

Diagnosis of this entity is fundamentally clinical, using diagnostic criteria proposed by Krause et al., [12], which are described in Table 1 . The patient in our case reported fulfilled all the aforementioned diagnostic criteria. Differential diagnosis of this entity should be made with other diseases with cutaneous involvement that appear in Table 2, some of which may require urgent treatment [13].

Table 1: Clinical criteria for the diagnosis of acute hemorrhagic edema of infant by Krause et al., [12].

\begin{tabular}{|c|}
\hline Clinical criteria for the diagnosis of acute hemorrhagic edema of infant \\
\hline$-\quad$ Age less than 2 years \\
\hline$-\quad \begin{array}{l}\text { Purpuric or ecchymotic target-like skin lesion with oedema on } \\
\text { the face, auricles and }\end{array}$ \\
\hline$-\quad$ extremities, with or without mucosal involvement \\
\hline$-\quad$ Lack of systemic disease or visceral involvement \\
\hline
\end{tabular}


Table 2: Differential diagnosis of acute hemorrhagic edema of infant.

\begin{tabular}{|ll|}
\hline Differential diagnosis of Acute Hemorrhagic Edema of Infant \\
\hline$-\quad$ Meningococcal sepsis \\
\hline$-\quad$ Schonlein-Henoch purpura \\
\hline$-\quad$ Erythema multiforme \\
\hline$-\quad$ Acute urticaria with hemorrhagic pattern \\
\hline - & Febrile acute neutrophilic dermatosis or Sweet syndrome \\
\hline - & Gianotti-Crosti syndrome \\
\hline - & Fixed drug eruption \\
\hline - & Child abuse \\
\hline EAHL: Edema Agudo Hemorrágico del Lactante
\end{tabular}

Skin biopsy reveals perivascular neutrophilic infiltrates that may associate endothelial edema with fibrin deposits in the vascular wall and extravasation of red blood cells [6]. Up to $30 \%$ of cases may show perivascular immunoglobulin A deposits [9]. The histopathological findings are identical to those of Schonlein-Henoch purpura, and there is great controversy over whether acute hemorrhagic edema and Schonlein-Henoch are different diseases or manifestations of the same process [1]. However, pathological anatomy is not necessary for diagnosis and is not performed systematically.

The clinical course of acute hemorrhagic edema is self-limited and benign, with resolution in days or weeks without sequelae or residual skin lesions, although recurrences are described [14]. There is no specific treatment and corticosteroids and antihistamines are not indicated because they have not shown any benefit in the resolution of the cutaneous sympthomatology $[14,15]$. It is recommended to maintain an expectant behavior, with symptomatic treatment [10]. Our patient presented a favorable evolution, with progressive disappearance of the lesions in 7 days, without presenting new outbreaks.

\section{CONCLUSION}

AHEI is an unusual form of leukocytoclastic vasculitis with cutaneous involvement, characterized by purpuric lesions and edema that usually affects male infants between 4 months and 2 years. In most cases it can be associated with an intercusrrent infections. Diagnosis is eminently clinical, being the knowledge of this entity important to maintain a high index of suspicion that avoids the systematic use of complementary tests. Differential diagnosis must be established with serious pathologies that may require urgent treatment. The AHEI presents a benign and self-limited clinical course, so expectant attitude is recommended.

\section{REFERENCES}

1. Cacharron Carames T, Diaz Soto R, Suarez Garcia F and Rodriguez ValcArcel G. (2011). Acute infantile haemorrhagic edema. An Pediatr (Barc). 74(4): 272-273.

2. Emerich PS, Prebianchi PA, Motta LL, Lucas EA, et al. (2011). Acute hemorrhagic edema of infancy: Report of three cases. An Bras Dermatol. 86(6): 1181-1184.

3. Roy KP, Madke B, Kar S and Yadav N. (2015). Acute hemorrhagic edema of infancy. Indian J Dermatol. 60(6): 624-625.

4. Checa Rodriguez R, Carabano Aguado I and Alvarez FernAndez B. (2015). Acute hemorrhagic edema in a newborn. Rev Pediatr Aten Primaria. 17: 151-153.

5. Braun-Falco M and Abeck D. (2002). Acute infantile haemorrhagic oedema. Lancet. 360(9328): 210.

6. Serra E, Moura Garcia C, Sokolova A, Torre ML, et al. (2016). Acute hemorrhagic edema of infancy. Eur Ann Allergy Clin Immunol. 48(1): 22-26.

7. Haeusler IL and Mohan R. (2018). Acute haemorrhagic oedema of infancy: A benign cause of a formidable rash. BMJ Case Rep. 2018 pii: bcr-2017-223368.

8. Fiore E, Rizzi M, Simonetti GD, Garzoni L, et al. (2011). Acute hemorrhagic edema of young children: A concise narrative review. Eur J Pediatr. 170(12): 1507-1511.

9. Yarmuch P, Chaparro R, Fischer S, Haussmann C, et al. (2012). Acute hemorrhagic edema of infancy. Case report. Rev Chil Pediatr. 83(5): 462-467.

10. Miner Kanflanka I, Vivanco Lopez A, Munoz Bernal JA, Landa Maya J, et al. (2004). Edema agudo hemorr Agico el lactante. Revision bibliogrAfica. Bol S Vasco-Nav Pediatr. 37: 13-16.

11. Saraclar Y, Tinaztepe K, Adalioglu G and Tuncer. (1990). Acute hemorrhagic edema of infancy a variant of HenochSchonlein purpura or a distinct clinical entity? J Allergy Clin Inmunol. 86(4): 473-483.

12. Krause I, Lazarov A and Rachmel A. (1996). Acute haemorrhagic oedema of infancy, a benign variant of leucocytoclastic vasculitis. Acta Paediatr. 85(1): 114-117.

13. Kuroda K, Yabunami H and Hisanaga Y. (2002). Acute 
Haemorrhagic Oedema of infancy associated with cytomegalovirus infection. $\mathrm{Br} \mathrm{J}$ Dermatol. 147(6): 12541257.

14. Roh MR, Chung HJ and Lee JH. (2004). A case of acute hemorrhagic edema of infancy. Yonsei Med J. 45(3): 523526.
15. Liu AJ, Hogan P and Nanan R. (2006). Acute Haemorrhagic Oedema of infancy. Arch Dis Child. 91(5): 382.

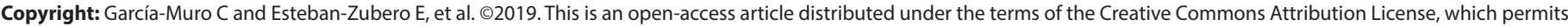
unrestricted use, distribution, and reproduction in any medium, provided the original author and source are credited. 